\title{
DiOMTOS
}

Revista de Comunicación Digital

\section{La agenda building de los partidos políticos españoles en las redes sociales: Un análisis de Big data}

\section{Spanish political parties' agenda building on social networks: A Big Data analysis}

Joaquín Martín Cubas
joaquin.martin@uv.es
Universitat de València

Emilio Soria-Olivas

emilio.soria@uv.es

Universitat de València

\section{Ángel LLosá Guillén}

angel.Ilosa.guillen@everis.com

Universitat de València

Vicente Buendía Ramón

vicente.buendia@uv.es

Universitat de València
Recibido: 05/11/2019

Aceptado: 28/02/2020

\section{Resumen}

Las redes sociales irradian un flujo de información de opinión horizontal y multimodal que ha abierto nuevos horizontes al análisis de los fenómenos políticos. La acción agregada de los ciudadanos en este nuevo ámbito permite orientar la agenda política del país e influir en la toma de decisiones públicas. El conocimiento de lo que ocurre en las redes deviene, pues, un objeto de estudio de primer interés. En este trabajo se utilizan metodologías sobre plataformas Big Data para analizar la evolución temporal de la agenda política marcada por los partidos políticos en las redes sociales, alguna de cuyas dimensiones quedan descritas mediante técnicas apropiadas de visualización. En la comunicación, que asume el marco teórico y metodológico del comportamentismo, se abordan, en primer lugar, las aproximaciones teóricas al fenómeno de la agenda setting o agenda building y las implicaciones que la aparición de las redes sociales digitales ha tenido en este terreno; en segundo lugar, las fuentes teóricas y procedimientos metodológicos de los análisis realizados en plataformas Big Data; y, en tercer lugar, un estudio empírico centrado en el estudio del uso de las redes por parte de algunos partidos políticos relevante de nuestro país, de sus militantes y de sus simpatizantes. Los resultados del estudio y su descripción a través de nubes de palabras permite hacerse una idea cabal sobre la imagen diferenciada que los partidos trasladan, consciente o inconscientemente, a los ciudadanos y ciudadanas que participan en la red y de la importancia que adquiere su control en su actividad diaria.

\section{Palabras clave}

Comunicación política, agenda política, agenda building, redes sociales, big data, partidos políticos

Cómo citar este artículo:

Martín Cubas, J.; Soria-Olivas, E. ; Llosá Guillén, A. y Buendía Ramón, V. (2020). La agenda building de los partidos políticos españoles en las redes sociales: un análisis de Big data. Dígitos. Revista de Comunicación Digital, 6: 253-274. DOI: 10.7203/rd.v1i6.165 


\begin{abstract}
Social networks radiate a horizontal and multimodal flow of opinion that has opened new horizons for the analysis of political phenomena. The aggregated action of citizens in this new field allows to guide the political agenda of the country and influence public decision-making. Knowledge of what is happening in the networks therefore becomes an object of study of prime interest. This paper uses methodologies on Big Data platforms to analyze the temporal evolution of the political agenda set by political parties on social networks, some of whose dimensions are describe using appropriate visualization techniques. In the article, which takes on the theoretical and methodological framework of behaviorism, addresses, firstly, the theoretical approaches to the phenomenon of agenda setting or agenda building and the implications that the emergence of digital social networks has had in this field; secondly, the theoretical and methodological procedures of the analyses carried out on Big Data platforms; and, thirdly, an empirical study centered on the analysis of the use of networks by some relevant political parties in our country, their militants and their sympathizers. The results of the study and its description though word clouds allow us to get a full idea of the differentiated image that the parties convey, consciously or unconsciously, to the citizens who participate in the network and the importance that their control acquires in their daily activity.
\end{abstract}

\title{
Keywords
}

Political communication, political agenda, agenda building, social networks, big data, political parties.

\section{La agenda building de los partidos políticos españoles} en las redes sociales: un análisis de Big data

\section{La construcción de la agenda política}

Los procesos de formación de la opinión pública es uno de los objetos más codiciados en la ciencia política -communication research-, al menos, desde que Walter Lippmann publicara Opinión pública en 1922. Lejos de creer en una opinión pública racional, Lippmann defendió la importancia de los medios de comunicación de masas a la hora de construir las imágenes o estereotipos de las que se nutren los ciudadanos para situarse en el ámbito político. Para la gran mayoría de los investigadores de la primera mitad del siglo XX, la sociedad de masas era un conglomerado de individuos aislados sobre los que los medios de comunicación podían ejercer una influencia persuasiva de forma directa (Fleur, M. L. De y Ball-Rokeach, S., 1986: 223). Las imágenes-metáforas elegidas para representar ese poder conformador de la opinión pública fueron la balalas ideas difundidas por los medios atraviesan el cerebro de los individuos de la misma forma que lo hace un proyectil- y/o la aguja hipodérmica -las ideas de los medios, en este caso, se inculcan en la mente de la misma forma que la aguja hipodérmica inyecta su líquido en el cuerpo humano-.

No obstante, esta imagen de único sentido de la cúspide de los media hacia los ciudadanos - modelo estímulo-respuesta- no ha recibido consenso unánime. A mediados del siglo XX se limitó el alcance del poder los medios por autores como Merton, Katz, Berelson, Hovland y/o Lazarsfeld. Estos autores entendieron que el poder de los medios se limita a reforzar opiniones ya existentes entre el público y, sólo en contadas 
ocasiones, pueden originar cambios de opinión relevantes entre la ciudadanía. Recalcaron, además, la importancia de la interrelación entre los individuos en grupos que, a través, del intercambio de ideas e información modulan el devenir de la opinión pública (Katz y Lazarsfeld, 1975). De hecho, sobre esta nueva base se construyeron las dos grandes teorías explicativas de los flujos de la comunicación en la época: la teoría de la exposición, percepción y retención selectiva según la cual los individuos, en términos generales, perciben, seleccionan y retienen sólo aquellos mensajes que se adaptan a sus ideas previas, evitando lo que Festinger llamó disonancias cognitivas (Lazarsfeld, Berelson y McPhee, 1954; Festinger, 1975) y la teoría de la influencia en dos fases según la cual las ideas de los medios de comunicación son pasadas por el tamiz de intermediarios, los líderes locales de opinión y los grupos en los que se integran (Lazarsfeld y Katz, 1975).

Los estudios de las siguientes décadas dotarían cada vez de mayor complejidad a los procesos de la comunicación. Aunque se puede establecer una clasificación muy detallista -modelos de difusión (en múltiples pasos, de innovaciones, de gap en los conocimientos, de difusión en J), modelo transitivo o de reconversión (teoría de las diferencias psicológicas individuales y modelo psicodinámico de Comstock), modelos de cambio en el nivel de influencia (teoría de la agenda setting y teoría de la espiral del silencio), paradigma de la búsqueda de la información (propuesta de inventario funcional y teoría de los usos y gratificaciones), modelo historicista y modelo de los efectos incuestionables (Vara Miguel, 2001); Ios teóricos de la comunicación suelen referirse de forma más genérica a tres grandes modelos de construcción de la opinión pública: Modelo de cascada; Modelo de bubble-up; y Modelo de identidad (Sartori, 2007).

En la segunda mitad del siglo XX autores como McCombs, o Robert Park, en la línea de Lippmann, hicieron hincapié en el importante papel de los medios para fijar la agenda política, especialmente marcando los temas sobre los que prestar atención y creando los marcos de interpretación desde los que concebirlos (Becker, McCombs y McLeod, 1975). De esta forma, la teoría de la agenda setting vino a cubrir el hueco explicativo dejado abierto por los enfoques anteriores (McCombs y Shaw, 1972). Los medios de comunicación de masas serían poderosos por indicar al público no qué pensar, sino sobre qué pensar a propósito de los asuntos de actualidad (Cohen, 1963: 120-121; Iguarta y Humanes, 2004: 244-245). Especialmente McCombs entendió que los medios no sólo influyen porque resaltan ciertos temas o problemas (priming, preparación o preactivación), sino porque proporcionan los estándares que el público utiliza para evaluar los fenómenos de la realidad que llegan a su conocimiento (framing o encuadre): "Los encuadres, pues, son maneras determinadas de organizar y estructurar la imagen de un objeto que disfruta de éxito entre el público" (McCombs, 2006: 179). Los medios, desde ese punto de vista, crean una realidad de segunda mano, un pseudo-entorno, que puede influir en el marco de referencia de los ciudadanos en cuanto a su visión de la política (Vara Miguel, 2001: 26) desempeñando un papel de construcción de la realidad social o, mejor, estructurando la imagen de la realidad, del imaginario social, al menos, a largo plazo (Rubio, 2009).

Aun así, la tesis de la teoría de la agenda setting ha sido puesta a prueba por la propia dinámica social. Por un lado, hay otros sujetos que participan en los procesos comunicativos de construcción de la agenda pública. Cada vez más los investigadores 
se han dedicado a profundizar en la cuestión de quién y cómo se establece la agenda de los medios y qué actores y fuentes son los más influyentes en la elaboración de los mensajes informativos de los medios (Vara, 2001: 33). Lo importante es, en cualquier caso, que en la actualidad en el ámbito público hay más sujetos pugnando por fijar la agenda, entre ellos los partidos políticos. Por otro lado, esa multiplicación de "sujetos influyentes" ha sido en gran parte permitido por la aparición de las redes sociales (Sierra y Lavín, 2019). De hecho, Parmelee concluye que las cuentas de los líderes políticos, de blogueros políticos y de think tanks o grupos de interés en Twitter lideran el proceso de agenda building, no solo por ser promotores de noticias, sino porque aportan ideas que permiten contextualizar y, eventualmente, corroborar datos (Parmelee, 2014; Aruguete, 2017). Las tecnologías digitales han puesto a disposición de los ciudadanos un número de medios de comunicación mayor - páginas personales, foros de debate, portales de contrainformación, weblogs-, medios que compiten con los grandes medios tradicionales pero no con las mismas reglas: se trata de medios altamente politizados, cuando no partidistas, en los que la realidad se configura cada vez en mayor medida merced a la acción interpretativa del propio público que crea su propio menú informativo, plural y personalizado (López, 2006: 46-49). Como afirma Vara Miguel, "se ha pasado así de un modelo de transferencia lineal de temas a un proceso de comunicación e influencias recíprocas mucho más complejo y dinámico en el que participan ciudadanos, políticos e informadores" (Vara, 2001: 34).

Por desgracia, han sido publicados pocos estudios que aborden esta cuestión, esto es, que estudien empíricamente la construcción de la agenda por parte de los partidos políticos (Seethaler y Melischek, 2919; Robles y Marco, 2019). En el ámbito anglosajón, existe una cierta tradición de estudio de la construcción de la agenda por los candidatos, especialmente durante las campañas electorales (Kruikemeier, 2014; Vergeer, 2015; Conwy, Kenskiy Wang, 2015). De estos estudios no cabe inferir que exista una mera transferencia de la agenda de los candidatos al público, aunque sí que la hay para afirmar su influencia desde el punto de vista de la formación ordenada de aspectos o atributos percibidos (Weaver, Graver, McCombs y Eyal, 1981; Vara, 2001: 46). Esa influencia ha llevado a presentar el efecto setting mediante dos círculos concéntricos: el exterior, la cáscara, recogería los asuntos o temas; y el interior, el núcleo, los atributos o aspectos, imagen en términos de Lippmann (Kosicki, 1993: 100-127). Como afirma Vara, "aunque la mayoría de las investigaciones han tomado estos dos aspectos -los asuntos y las imágenes, como realidades separadasalgunos estudiosos afirman que ambas se mezclan e influyen en la decisión de voto de los ciudadanos" (Vara, 2001: 50).

En España poco a poco se empieza a estudiar el impacto de las redes -y, en especial, de Twitter- en la comunicación política (Gelado, Rubira y Navío, 2019; Robles y Marco, 2019). Nosotros en este trabajo vamos a explorar la producción de esos asuntos e imágenes en términos muy generales -el detalle se deja para posteriores trabajos-, no por parte de los candidatos en una campaña electoral sino por parte de los partidos políticos en un contexto valle entre campañas electorales. Nos situamos, pues, en los planteamientos de la agenda setting o agenda building, pero aplicada a la agenda construida por los partidos políticos -no tanto por los medios o el propio público- en su vertiente de estudio de los temas, conceptos o imágenes que se enfatizan a través de los términos que se utilizan (construcción, consciente o inconsciente, de marcos -frames- desde la intención de condicionar los criterios del público para juzgar al partido político - priming-). 


\section{Las redes sociales, el Big Data y la metodología de análisis}

Los partidos políticos son conscientes de la importancia de las redes sociales para construir una imagen de sí mismos, aunque en nuestro país han sido remisos a adaptarse a la nueva realidad digital. En 2010 IntelligenceCompass realizó un estudio donde inquirió a una muestra de nuestros políticos sobre estas cuestiones. De ese estudio se desprendía que: prácticamente el $99 \%$ de los políticos valoran de forma positiva las Redes Sociales, por lo que quieren y buscan tener presencia en ellas; los políticos utilizan las Redes Sociales por un sentimiento de aspiración a tener mayor contacto con el entorno más próximo y con el ciudadano; saben que en el futuro las redes sociales van a jugar una importante baza en la relación con el ciudadano y a la postre en las elecciones. Pese a esa convicción el mismo estudio concluía "en España el político no es capaz de encender la chispa que haga que este modelo se ponga en marcha por lo que, hoy por hoy, la ola Obama no llegará a nuestras costas" (IntelligenceCompass, 2010: 11).

Una red social comunica entre sí a individuos y a colectivos mediante características basadas en asociaciones, relaciones de amistad, familiares, gustos y aficiones similares, creencias y conocimientos. Aunque los participantes no necesariamente pretendan contactar con desconocidos, sí interesan de comunicarse con otros participantes de sus redes de incumbencia. Esta cualidad es la que proporciona a las redes sociales su nombre (Boyd y Ellison, 2007). Las redes sociales y las herramientas de microblog como Twitter se utilizan para expresar sentimientos y opiniones en forma de mensajes de texto cortos. Además, han llegado a ser uno de los canales más importantes para la retransmisión de noticias (Kwak y col., 2010). Consecuentemente, la aplicación del análisis de sentimiento social cubre un amplio rango de ámbitos incluyendo noticias, tecnología, comercio electrónico, salud, y política. Las redes sociales fomentan la discusión y deliberación política y las opiniones confrontadas se utilizan para predecir los resultados de las elecciones (Dokoohaki y col., 2015; Wang y col., 2012; Hasan y col., 2017). Obsérvese como ejemplo el caso de la campaña presidencial de Costa Rica en 2014 (Romero, 2015); la Figura 1 muestra una comparativa donde se relacionan actividad en redes sociales, encuestas previas de opinión y resultados finales.

Como se observa, aunque con matices, existe una correspondencia entre resultados electorales, encuestas de opinión y la actividad en Facebook, que sirve como medición de movilización pública. De lo anterior se deduce que el análisis de opiniones y sentimientos asociados es crucial para el éxito de toda campaña. Sin embargo, existen dos dificultades significativas que deben salvarse: en primer lugar, las redes sociales producen grandes volúmenes de datos, por lo que el empleo de métodos manuales es impracticable; en segundo lugar, debe implementarse una interpretación eficaz de sentimientos y emociones. No obstante, en este trabajo no pretendemos descender a estudiar estos aspectos emotivos que se relacionan con la dimensión afectiva de la política, esto es, no nos preocupa en este momento estudiar el tono positivo, negativo o neutro con el que se dibujan los perfiles de los partidos políticos en las redes digitales, sino más bien la dimensión más sustantiva de lo que a través de las nubes de palabras se destaca para los distintos partidos en su discurso volcado en la red. De alguna forma, pretendemos bucear en la imagen que los partidos trasladan desde el inconsciente de su militancia y de sus "aparatos" digitales. En este trabajo se analizarán las redes 
sociales mediante el estudio de sus variaciones temporales. Se realizará un análisis de atributos e imágenes y se visualizarán los resultados mediante técnicas apropiadas de visualización con el objetivo de describir la evolución de la opinión pública española.

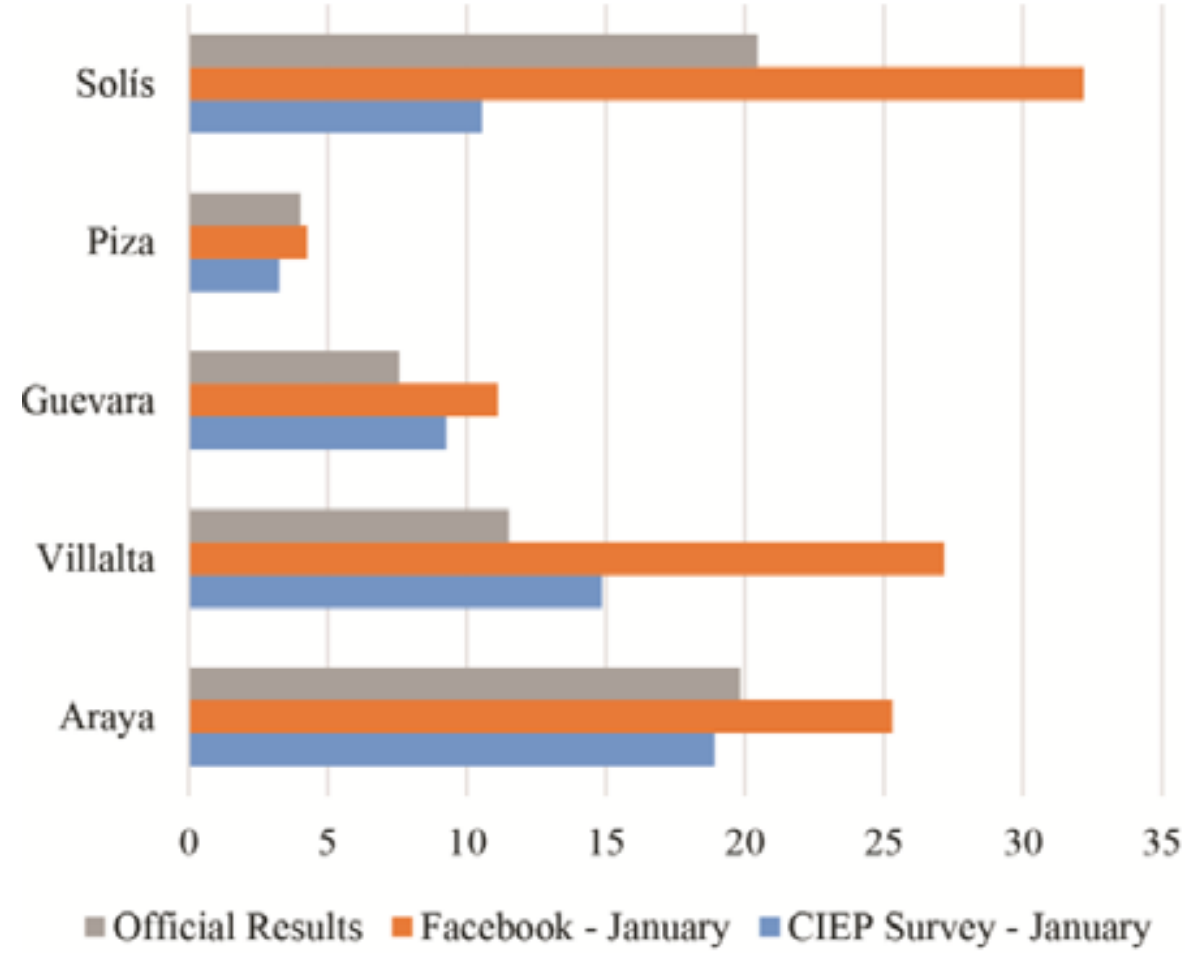

Figura 1: Comparativa de resultados electorales, actividad en redes sociales $y$ encuesta previas de opinión (Romero, 2015). La actividad se mide en cantidad percentual de aportaciones y comentarios.

Las herramientas Big Data surgieron para poder analizar el comportamiento de los usuarios en plataformas online (Ghemawat, Gobioff y Leung, 2003 o Dean y Ghemawat, 2004). Para poder realizar análisis más detallados y precisos, pronto empezaron a surgir herramientas que permitían utilizar algorítmica avanzada, como aprendizaje automático. Así se conseguía analizar los grandes volúmenes de datos generados en tiempo real y se podía reaccionar al comportamiento del usuario en ese instante. Por este motivo, y de manera natural, se ha extendido el uso de estas plataformas para resolver problemas similares: gran afluencia de datos y toma de decisión automática.

En concreto, uno de los casos de uso típico es el análisis de las redes sociales. El tipo de información a analizar que se escoge es normalmente la que está en modo texto, debido a que las técnicas de análisis de este tipo de información están muy avanzadas. Las técnicas de procesado de lenguaje natural han sido desarrolladas desde los años 60 (aitr71), y con la llegada de las plataformas Big Data ha tomado un nuevo impulso gracias a herramientas de desarrollo como Mapreduce (Dean y Ghemawat, 2004), y en los últimos años Spark (spark_zaharia).

Con estas herramientas y la posibilidad de analizar toda la información generada tanto por lotes como en tiempo real, el mundo de la política es el campo ideal para sacar partido a estas técnicas (González, 2019). Por ejemplo, en (Watts y col., 2016) se presenta un método de análisis predictivo, en el que a través del análisis de sentimientos de los mensajes en la red social Twitter relacionados con la campaña, se va calculando de manera dinámica el impulso de la campaña, para predecir el ganador. También en (Fatta y 
col., 2015) se proponen distintos análisis de las elecciones generales del 2015 en Gran Bretaña, tanto off-line como en tiempo real, de los tweets recogidos de Twitter. En este se analizan momentos concretos de la campaña electoral con algoritmos de procesado de lenguaje natural o visualización de nubes de palabras.

Para la obtención de los datos se ha utilizado la API de Twitter de tiempo real. A través de esta se pueden obtener los tweets que se están publicando en tiempo real, filtrados por geoposicionamiento y/o por etiquetas. Éstas pueden ser palabras o hashtags. En este caso, no se ha filtrado por geoposicionamiento y se han realizado dos filtrados distintos:

\section{- Filtrado en la obtención de los datos:}

Para obtener los tweets se ha consultado por términos distintos a palabras de uso común:

psoe, pp, pnv, compromis, sanchezcastejon, siessi, susanadiaz, LosPrimeros1000, Patxilopezpsoe, SocialistasConPatxi, MilitantesEnPie, ConPatxiLopez, ahorapodemos, CiudadanosCs, marianorajoy, Pablo_Iglesias_, Albert_ Rivera, PPopular.

\section{Filtrado en el tratamiento de los datos:}

Se han eliminado los retweets

Se han agrupado los tags por partidos:

- Podemos<-["Pablo_Iglesias_","ahorapodemos"]

•Pp<[“@ppopular","pp","PartidoPopular","PPopular","marianorajoy"]

Psoe<-["psoe"+psoe_pedro+psoe_susana+psoe_patxi]

- Compromis<-["compromis"]

Pnv<-["pnv"]

Ciudadanos<-["Albert_Rivera","CiudadanosCs"]

Se han bloqueado las siguientes palabras en las nubes:

- Palabras inferiores a 3 letras

- Nombre de partidos políticos

A destacar en la obtención de los datos:

- Se ha evitado utilizar palabras comunes (por ejemplo, podemos, ciudadanos, etc.) para no obtener mensajes no relacionados con la política.

- Se ha recopilado datos en el intervalo de cuatro meses: febrero (desde el día 14), marzo, abril y mayo del 2017.

- Las fechas han coincidido con el arranque de las elecciones de la secretaría general del PSOE.

Una última aclaración es que en este trabajo hemos partido de la hipótesis según la cual para cada partido los participantes en la red que ayudan a construir su imagen, por acción u omisión, son principalmente los integrantes de sus aparatos políticos, sus militantes y simpatizantes digitalmente comprometidos, más allá de la necesaria intervención de ciudadanos críticos partidarios de otros partidos o no comprometidos. 


\section{Resultados de la investigación}

Los resultados de la investigación, una vez analizados los datos obtenidos a través de las técnicas y metodología descritas, son resumidos a continuación a través de una estructura tripartita: en primer lugar, la imagen o atributos proyectados por cada uno de los partidos -aparatos, militantes o simpatizantes, especialmente- de forma individual en la red; en segundo lugar, se procede a realizar una comparación entre las imágenes $y$ atributos de los diferentes partidos; $y$, finalmente, hemos reservado un epígrafe especial a la campaña electoral a la secretaría general del PSOE de los tres candidatos -Patxi López, Pedro Sánchez y Susana Díaz- que se enfrentaron en las mismas fechas en la que recogíamos los datos de las redes para el presente estudio.

\subsection{La imagen de los partidos}

Los partidos analizados son seis: Ciudadanos, Compromís, PNV, Podemos, PP y PSOE.

\subsubsection{Ciudadanos}

Las nubes de sus tags presentan por encima de todo un partido de liderazgo presidencialista. Durante los cuatro meses, Albert Rivera es la expresión más utilizada, reforzada a distancia por la expresión presidente. En torno al 7\% de los tweets, frente al resto de las palabras, entre las cuales las más utilizadas apenas alcanzan medio punto.

Tabla 1: Nube de palabras en las redes de Ciudadanos: febrero-mayo 2017. | Elaboración propia

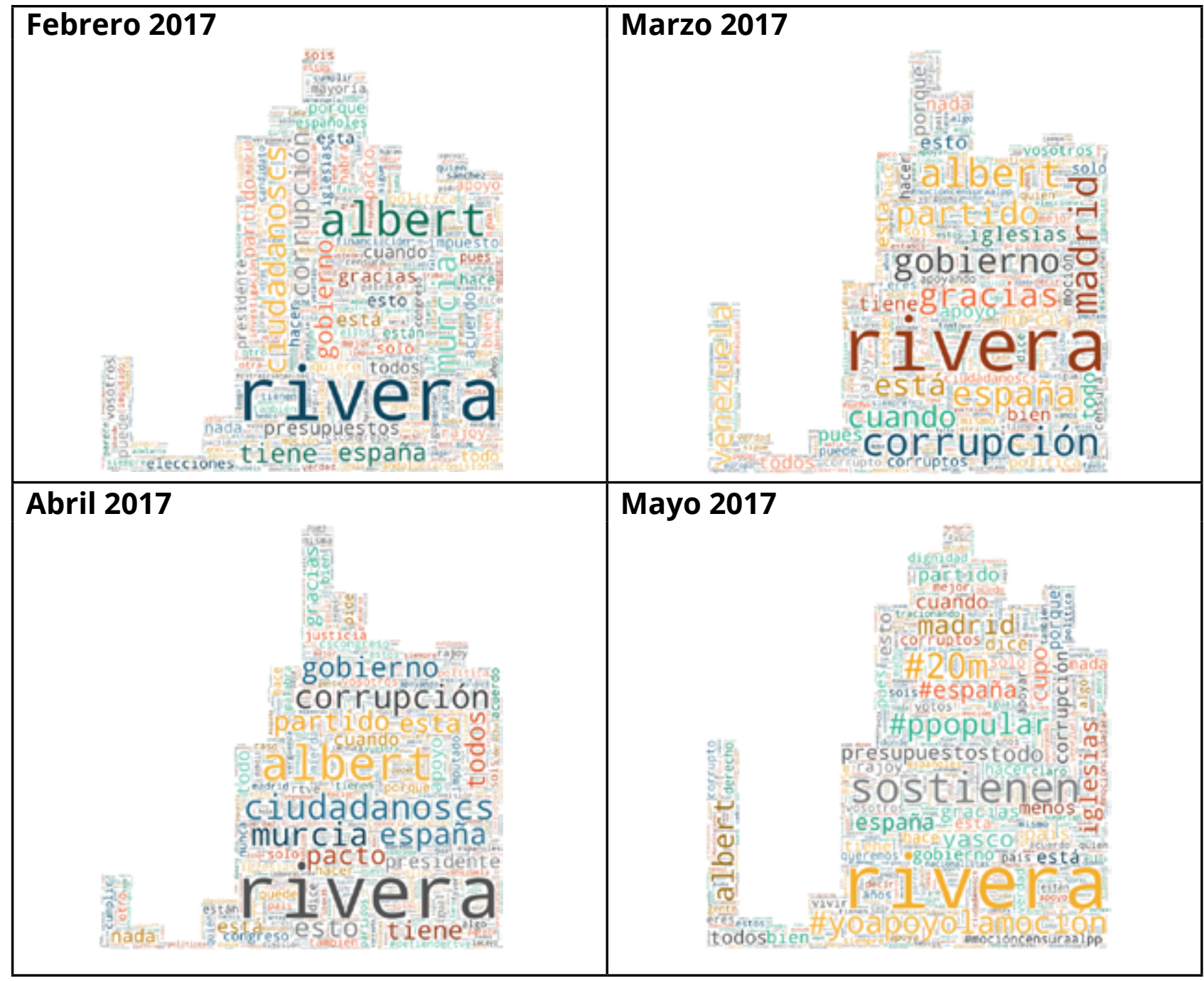


El segundo bloque de atributos se relaciona con el partido. Junto con Albert Rivera aparece siempre destacada el nombre del partido, Ciudadanos, conformando una especie de tándem referencial. Pero, además, el partido aparece ligado a valores positivos. Destacan las palabras España, gobierno, partido, pacto. Ciudadanos se presenta como partido de gobierno capaz de salvar a España mediante el pacto de gobierno con el PP. Ese mensaje se refuerza con otros mensajes: apoyo, todos, gracias, justicia.

Un tercer bloque de atributos que se destaca es el referido a la crítica de la corrupción ya sea de forma directa -uso frecuente del término corrupción- o referido al caso de actualidad -en este caso, Madrid-.

Estas constantes sólo se ven afectadas por dos hechos de actualidad que inciden en la agenda de Ciudadanos: por un lado, la moción de censura al presidente del gobierno presentada por Podemos que les obliga a posicionarse en un sentido crítico lo que puede explicar la aparición con cierta fuera de la palabra Venezuela (también durante este mes aparece con fuerza la expresión Sostienen cuyo significado es ambiguo); y la negociación del cupo vasco en relación al cual también aparece reflejada la preocupación del partido.

\subsubsection{Compromís}

Las nubes de sus tags presentan por encima de todo un partido cohesionado en torno a la propia marca y su significado. En ningún momento destaca la presencia de un líder y eso a pesar de que mediáticamente sí que existe un fuerte reconocimiento al liderazgo en este partido de Mónica Oltra. Quizá la naturaleza de coalición del partido condiciona el hecho de que las referencias al nombre del partido, Compromís, o a su significado compromiso, compromisos o compromisarios- se sitúe en toda la serie aproximadamente en los siete puntos, muy alejado del resto de palabras que no alcanza un punto salvo en ocasiones la expresión gobierno.

En un segundo nivel de referencias aparecen las palabras gobierno y congreso ligadas a la proyección institucional que ha alcanzado este partido tras las últimas convocatorias electorales: gobierna en la Comunidad Valenciana y en muchos de sus municipios y tiene una representación relevante y significativa en el Congreso de los diputados (también está representado en el Senado).

En ese sentido, el tercer nivel aunque ya muy alejado de las anteriores se relacionan con la defensa de lo propio: valencia, valencianos, lo nuestro, autogobierno, con una mención destacada a Alicante pero ya mezcladas con una bruma de palabras donde según la coyuntura saltan a la palestra temas de actualidad en la Comunidad Valenciana (menos, de España): contratos predoctorales, corrupción, zombi, apocalipsis, explicaciones, barraka, tranvía, basset, alcohol, pide, confidencial,... 
Tabla 2: Nube de palabras en las redes de Compromís: febrero-mayo 2017. | Elaboración propia.

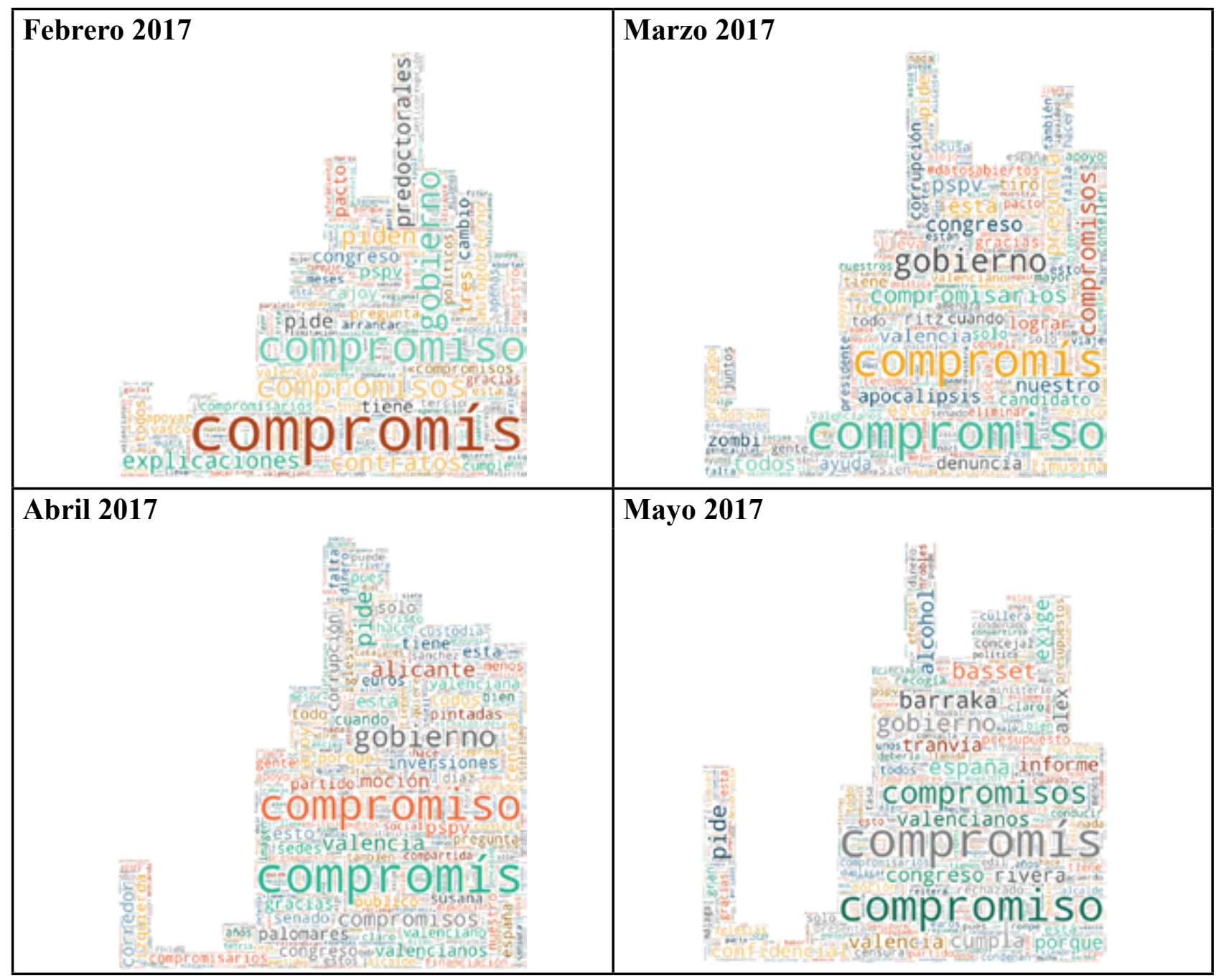

\subsubsection{PNV}

En el caso del PNV lo más destacable -y en buena parte lo único destacable- es la referencia constante a la negociación de los presupuestos con el gobierno y el do ut des que se establece entre los gobiernos vasco y español: dinero a cambio de apoyo. En ningún momento aparece ninguna referencia destacable al partido -PNV-aunque alguna hay (sí que aparece la referencia a Bildu, fenómeno que les interesa) ni mucho menos a liderazgos personalistas, ni el nombre del líder del partido ni el del Lendakari.

En todo caso, destaca la palabra presupuestos y otras concomitantes: dinero, ganar; una especie de trío inescindible con otros dos grupos: por un lado, gobierno, Rajoy, congreso, estado, España. Junto a ellas, ligadas irremediablemente, negociación, deshielo, apoyo, acuerdo, pacto, pleno, enmienda, ganar, millones.

Junto a estas, salvo la aparición de algún caso menor de actualidad como estiba, destaca la referencia identitaria, vascos o Euskadi, y en abril la aparición con fuerza del término cosoberanía, ligado, como no puede ser de otra forma, al proceso de negociación del cupo vaso. 
Tabla 3: Nube de palabras en las redes de PNV: febrero-mayo 2017. | Elaboración propia.

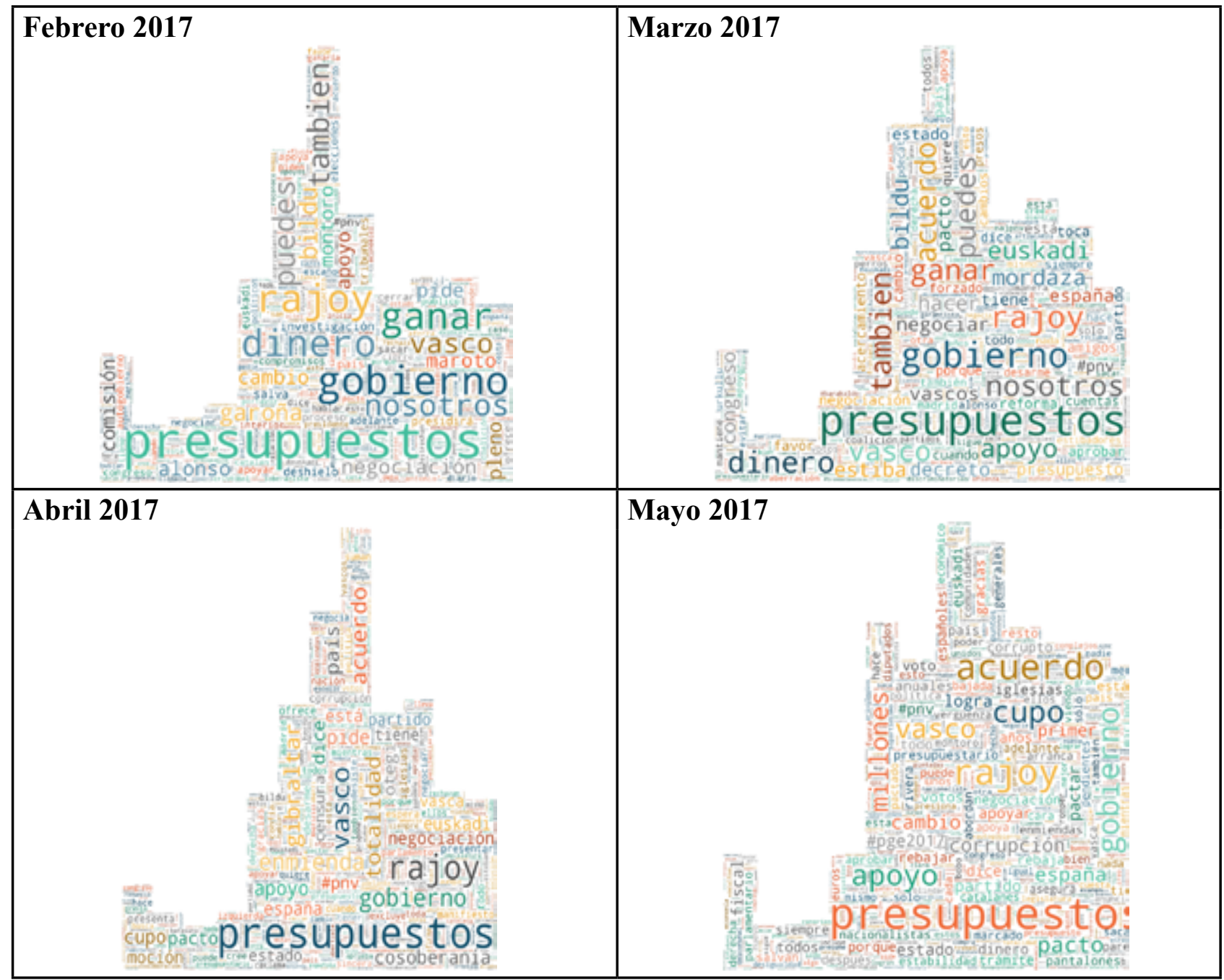

\subsubsection{Podemos}

El partido Podemos sin duda se sustenta y define como partido de liderazgo fuerte. La palabra con diferencia más empleada es Pablo Iglesias que alcanza en toda la serie en torno a 17 puntos; convirtiendo de esta forma todo lo demás, con los matices que ahora veremos, una especie de desierto en el que lo único que importa es el líder. Sólo en febrero los nombres de Iñigo Errejón e Irene Montero alcanzan algo de notoriedad fruto de la coyuntura caracterizada por la sustitución del número dos del partido, en el partido y en el Congreso de los Diputados. De la misma forma en el mes de mayo se introduce de forma relevante aunque no con demasiada fuerza la referencia a la moción de censura presentada por Pablo Iglesias contra el gobierno de Rajoy.

Salvo estos temas coyunturales las únicas constantes que se pueden destacar, aun en un marco general de indiferencia, son las referencias a Venezuela y a España. 
Tabla 4: Nube de palabras en las redes de Podemos: febrero-mayo 2017. | Elaboración propia

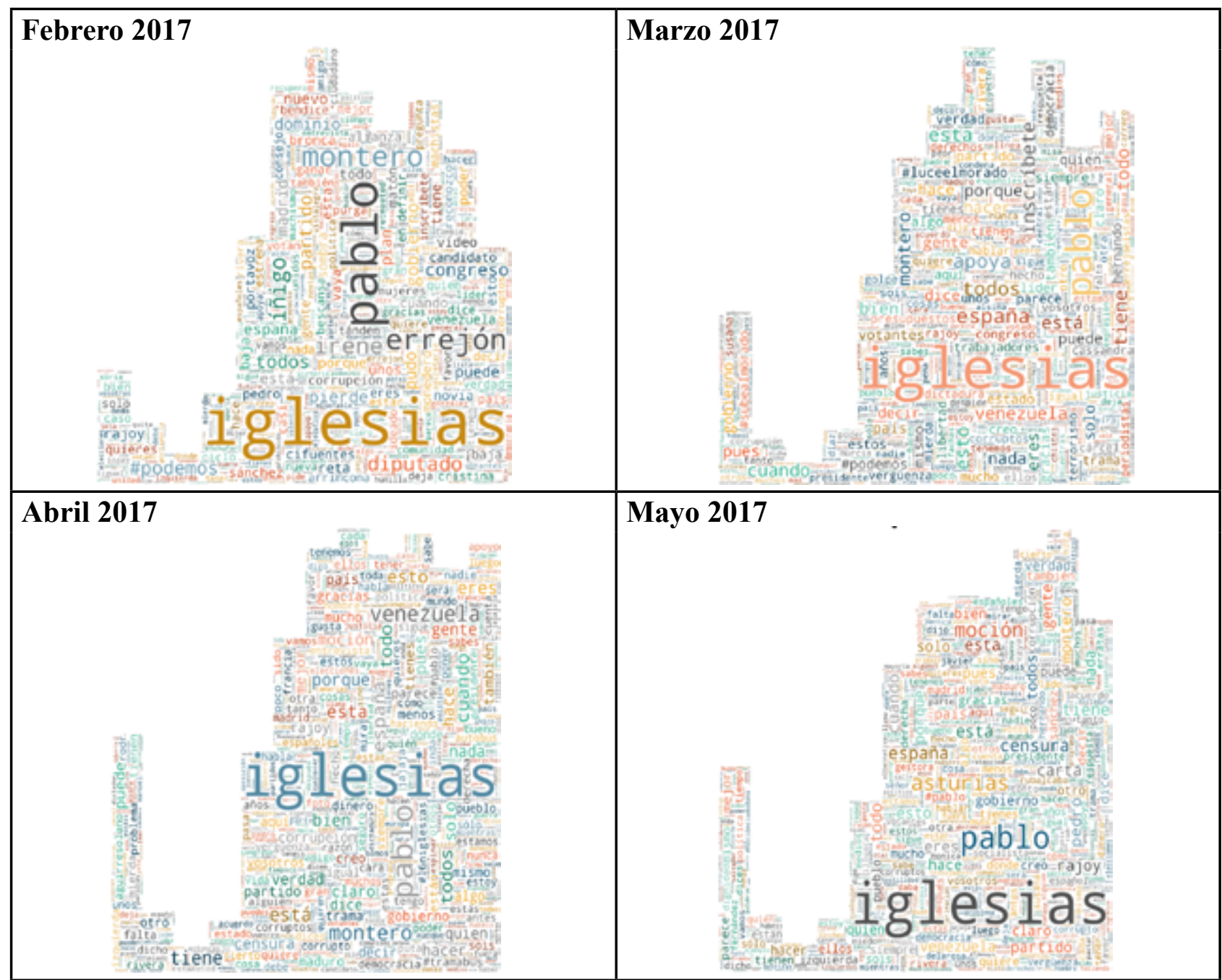

\subsection{5. $P P$}

En el caso del PP no hay términos especialmente destacables pero sí grupos de palabras que denotan las preocupaciones de este partido. Destaca por encima de los demás las referencias a la corrupción ya sea directamente con esta expresión o de forma indirecta a través del nombre de los casos más relevantes en cada momento o de las personas implicadas en ellos: Madrid, Murcia, Ignacio González o Esperanza Aguirre.

En segundo lugar, destaca un grupo de palabras que juntas adquieren sentido gobierno, España, partido y Rajoy. Todas ellas o casi todas aparecen en los primeros puestos entre las diez palabras más citadas.

Las demás referencias destacables obedecen a las distintas coyunturas: en febrero, Cospedal y Cifuentes, junto con referencias menores a Rivera, Sánchez o Iglesias; en marzo, congreso y financiación; en abril, sigue, aunque con menos fuerza, financiación; y en mayo, con motivo de la moción de censura presentada contra Rajoy, aparece con fuerza Pablo Iglesias y también Presupuestos y términos ligados como dinero, millones, euros, acuerdo.

Desde otra perspectiva, en el caso del PP, podemos destacar el hecho de que su líder y presidente del gobierno, Mariano Rajoy, aparezca bastante diluido entre otras palabras 
más extendidas, posiblemente fruto de la influencia de una estrategia preconcebida para presentarlo con un perfil bajo ante el impulso mediático de la corrupción ligada al PP. Significativa también, aunque con poca relevancia, es la referencia a Castilla.

Tabla 5: Nube de palabras en las redes de PP: febrero-mayo 2017. | Elaboración propia

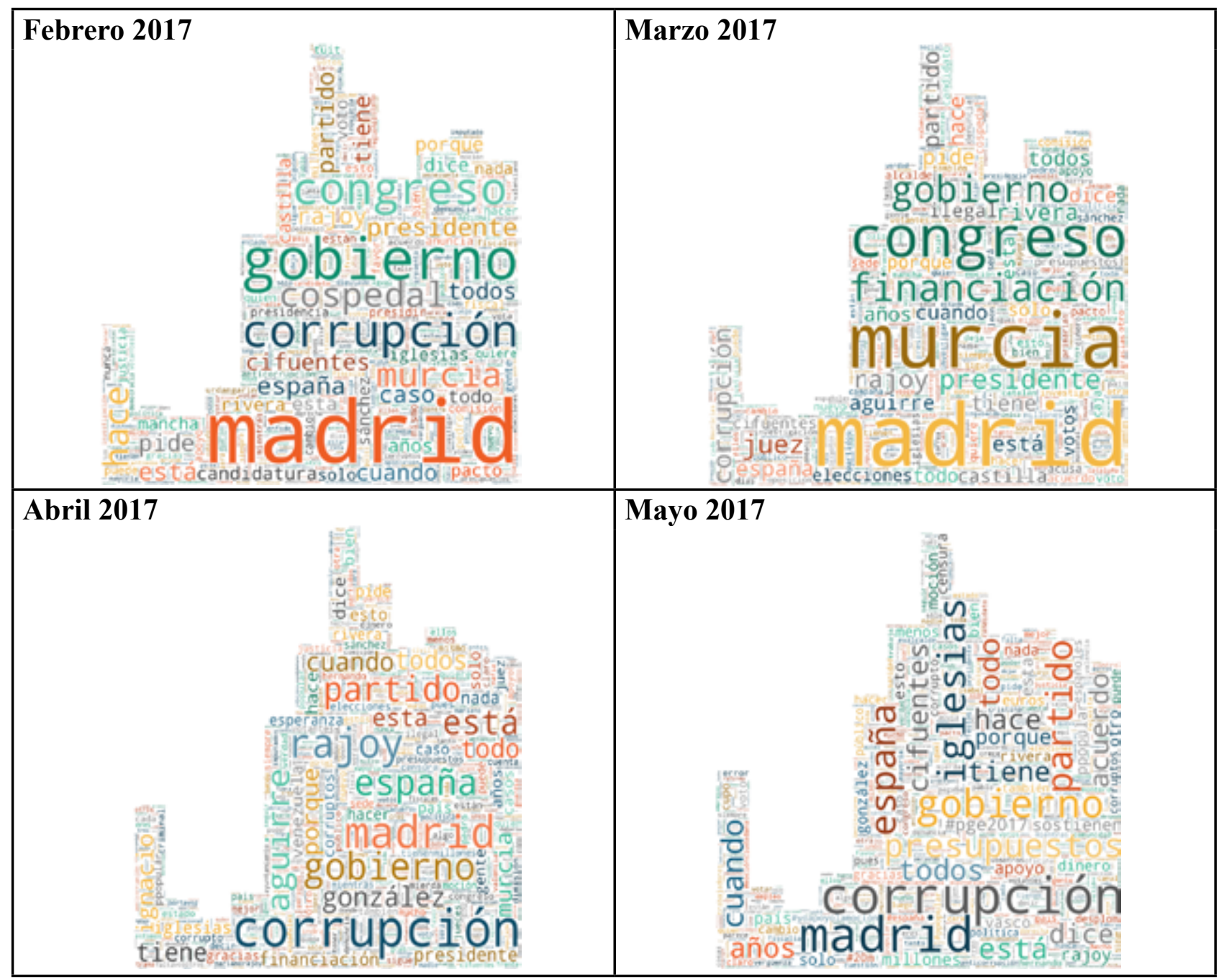

\subsubsection{PSOE}

En el caso del PSOE, inmerso en el proceso de primarias, prevalecen las cuestiones de coyuntura: primarias, negociación del CETA, moción de censura. Su impacto en la agenda deriva más del propio proceso interno de primarias para elegir su líder que de cuestiones de contenido político en relación a los problemas de gobierno. Incluso el debate sobre el CETA queda referenciado en una clave interna.

Sobre todo y en un primer nivel destacan las referencias al debate interno de primarias con dos nombres propios, Pedro Sánchez y Susana Díaz, no teniendo prácticamente relevancia la candidatura de Patxi López. Los tiempos del proceso quedan perfectamente marcados: en febrero, las referencias a Pedro Sanchez arrasan en buena parte debido al retraso en presentar su candidatura Susana Díaz; en marzo, cuando ésta presenta su candidatura, aparece con fuerza en primer lugar de las referencias, desplazando a Pedro Sánchez; en abril, Pedro Sánchez recupera su lugar preferente acompañado de la marca \#siessi; en mayo, Pedro Sánchez se queda ya prácticamente solo una vez derrotada Susana Díaz. 
Tabla 6: Nube de palabras en las redes de PSOE: febrero-mayo 2017. | Elaboración propia

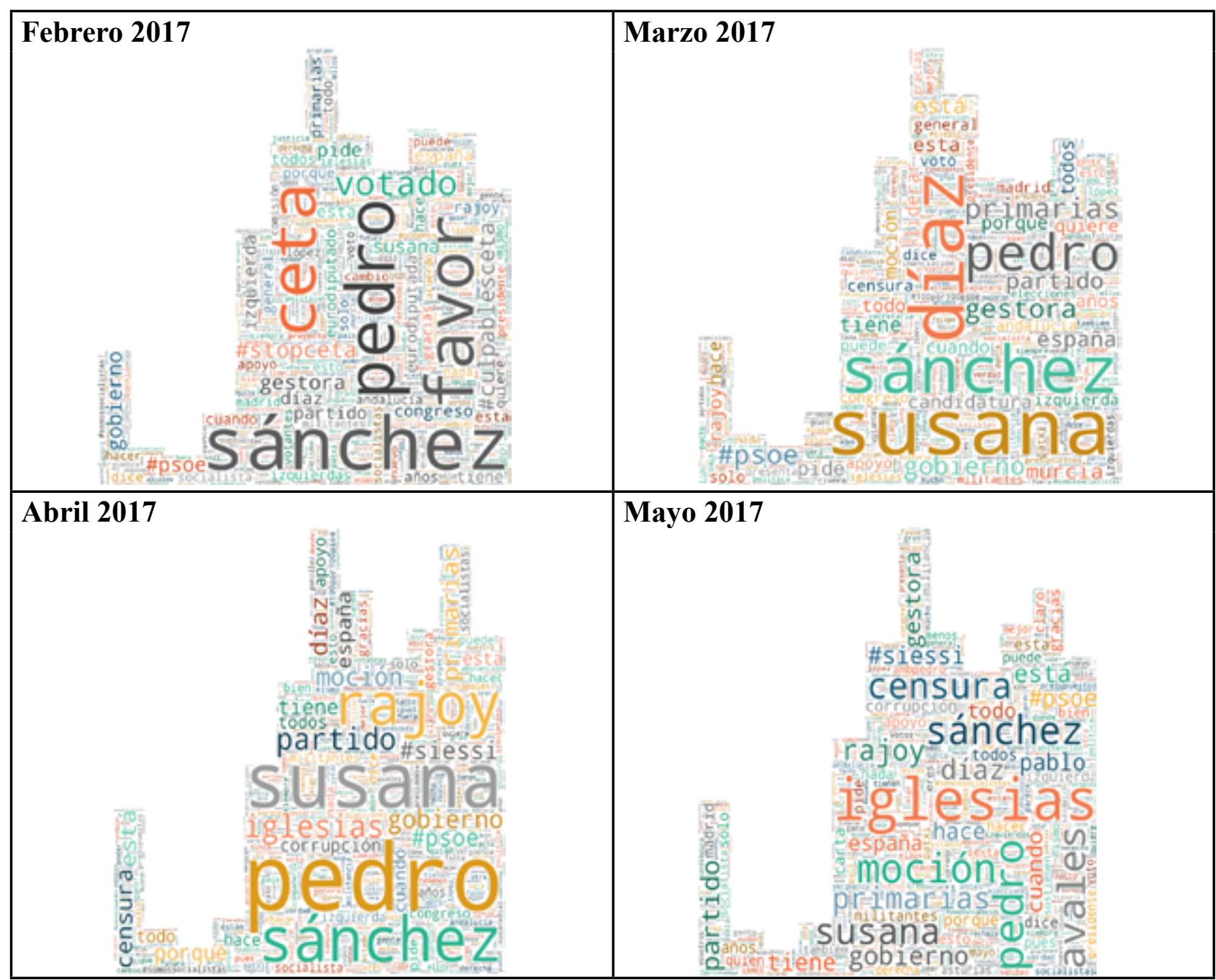

En un segundo nivel aparecen durante toda la serie las referencias al partido vinculadas al proceso que están viviendo de primarias -la gestora, las primarias, la izquierda- y al gobierno con las expresiones vinculadas desde el punto de vista institucional -congreso y presidente-.

También la coyuntura marcará otras referencias destacables. En el mes de febrero, por ejemplo, aparece con fuerza en los tweets socialistas las referencias al debate sobre el tratado CETA -y expresiones vinculadas como eurodiputado/a- en muchos casos en términos de rechazo.

En los meses de abril y mayo especialmente se cuela con mucha fuerza las referencias a la moción de censura presentada por Pablo Iglesias a Mariano Rajoy, hasta el punto que en el mes de mayo la palabra más citada en los tweets socialistas es Iglesias, por encima de Pedro o de Sánchez que, eso sí, sumadas ocuparían el lugar más destacable.

Es una constante en toda la serie las referencias significativas, aunque no especialmente destacable, a España y a la corrupción (Murcia). 


\subsection{Comparación entre partidos}

El estudio realizado sólo permite realizar una aproximación a las imágenes que los partidos políticos de referencia, a través de sus aparatos, militantes y simpatizantes comprometidos digitalmente, construyen de si mismos y de su capacidad de incidir en la agenda pública. Son obvios, además, los límites de esta comparación porque sólo pueden referirse al espacio temporal acotado por el estudio y a las redes sociales. No obstante ello, aparecen algunas pautas significativas en el comportamiento en la red de cada uno de ellos. Para apoyar nuestro análisis nos valdremos de una tabla que resume los principales temas de incidencia de cada partido.

Tabla 7. Comparación entre las imágenes y atributos de cada partido político referenciado: febrero-mayo 2017. | Elaboración propia.

\begin{tabular}{|c|l|l|l|l|l|l|}
\hline \multicolumn{2}{|c}{ Ciudadanos } & Compromís & \multicolumn{2}{c|}{ PNV } & \multicolumn{2}{c|}{ Podemos } \\
$1^{\circ}$ & Albert Rivera & $\begin{array}{l}\text { Compromís } \\
\text { (partido) }\end{array}$ & Presupuestos & $\begin{array}{l}\text { Pablo } \\
\text { Iglesias }\end{array}$ & Corrupción & $\begin{array}{l}\text { Primarias } \\
\text { Pedro S } \\
\text { Susana D }\end{array}$ \\
\hline $2^{\circ}$ & $\begin{array}{l}\text { Ciudadanos } \\
\text { (partido) }\end{array}$ & $\begin{array}{l}\text { Gobierno y } \\
\text { Congreso }\end{array}$ & $\begin{array}{l}\text { Vascos/ } \\
\text { Cosoberanía }\end{array}$ & $\begin{array}{l}\text { Moción } \\
\text { censura }\end{array}$ & $\begin{array}{l}\text { Gobierno } \\
\text { España } \\
\text { (Rajoy) }\end{array}$ & $\begin{array}{l}\text { Partido } \\
\text { Gobierno }\end{array}$ \\
\hline $3^{\circ}$ & $\begin{array}{l}\text { Crítica } \\
\text { corrupción }\end{array}$ & $\begin{array}{l}\text { Valencianos/ } \\
\text { Lo nuestro }\end{array}$ & & & & \\
\hline
\end{tabular}

Resulta clara que las prioridades de los partidos son diferentes. Si atendemos a las palabras más destacadas en cada uno de ellos:

- Ciudadanos y Podemos, partidos de la llamada nueva política -si ésta existe en algún sentido-, se decantan por el liderazgo visualizando más a sus respectivos líderes.

- Compromís, por el contrario, se decanta por el partido y sus connotaciones, dejando de lado el liderazgo. Ya hemos comentado que se trata de una coalición de partidos.

- PNV tiene claramente un perfil pragmático al decantarse con claridad por los presupuestos y los posibles beneficios a obtener de ellos.

- El PP, forzado por sus propias circunstancias, se ve abocado a reflejar sus penurias judiciales en torno a los casos de corrupción que le salpican.

- El PSOE, también forzado por sus circunstancias, refleja en sus tweets el debate de primarias y no tanto el liderazgo como tal.

Ahora bien, si ampliamos la mirada a segundas y terceras prioridades e introducimos el peso con la que cada una de ellas está reflejada en la distribución de las palabras en los tweets surgen nuevos matices en la comparación. Por ejemplo:

Si bien tanto Ciudadanos como Podemos destacan por la afirmación de su liderazgo personalista, el peso de esos liderazgos es diferente. Mientras que Pablo Iglesias mantiene una relación como mínimo de 17 a 1 frente a cualquier otra expresión, la de Albert 
Rivera se reduce a la mitad, 8 a 1 . Además, mientras que en el caso de Podemos no hay otro atributo relevante, salvo el de la moción de censura, muy avanzado el espacio temporal analizado; en el caso de Ciudadanos, junto al líder Albert Ribera, aparecen otros atributos como el Partido Ciudadanos y un claro mensaje político de crítica a la corrupción. En Podemos, sin embargo, esto no ocurre.

Sugerente también es la comparación entre dos partidos de corte nacionalista como son Compromís y PNV. Los contextos históricos de cada uno de ellos probablemente condicionan sus propuestas en la red. Ya hemos visto como Compromís se decanta por afirmar su imagen de partido político (la relación de las referencias a Compromís frente a otras palabras es de 7 a 1), a lo que une si interés en fijar una imagen institucional relacionada con su presencia en el gobierno valenciano y en el Congreso, frente al pragmatismo del PNV, que si bien refleja ese aspecto institucional lo hace en el marco de la negociación de los presupuestos (cupo) para Euskadi (relación de 8 a 1). Además, en los dos, como partidos nacionalistas que son, aparece reflejada su marca identitaria, valenciana y vasca respectivamente, si bien con matices de interés pues en el primer caso se queda en una defensa de lo nuestro frente al segundo caso donde es interpretada en clave de cosoberanía.

Tabla 8: Comparativa nubes de palabras en las redes sociales durante el mes de abril de 2017: Cs, Cmpr, PNV, Pds, PP, PSOE. | Elaboración propia

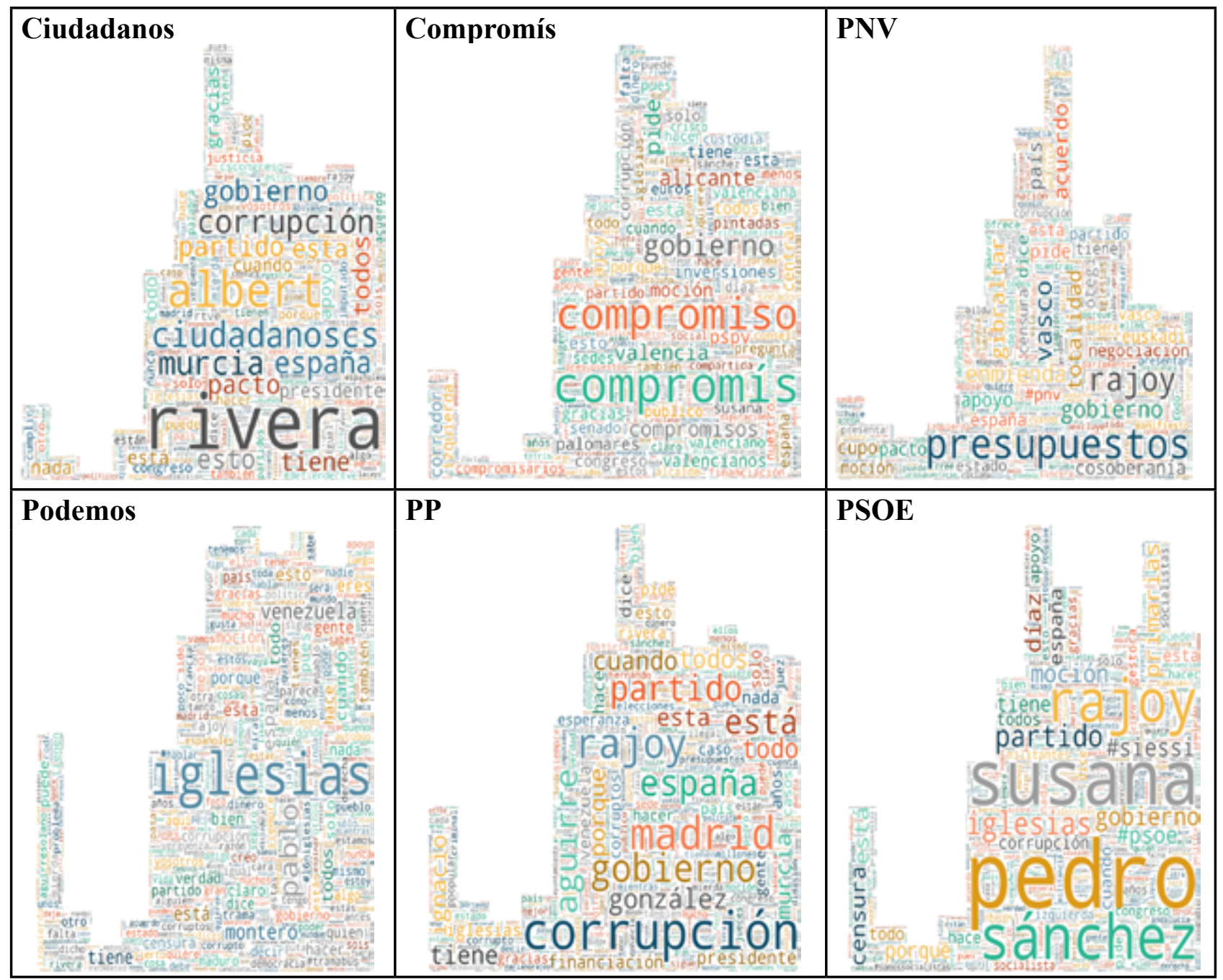


Interesante también resulta la comparación entre los dos partidos de gobierno tradicionales en nuestro país. Los tweets reflejan que su crisis sigue vigente y posiblemente se alargue en el tiempo, al menos en el primer caso. Hemos visto que sus crisis respectivas aparecen reflejadas en las palabras más reiteradas en sus tweets: corrupción para el PP (relación de 2 a 1) y crisis de liderazgo en forma de primarias para el PSOE (relación de 3 a 1). No es de extrañar, pues, que ambos partidos pugnen por contrarrestar esa mala imagen con el intento de afianzar sus imágenes como partidos de gobierno. Resulta, por lo demás, sintomático de las consecuencias de la crisis para el PP que su líder, Mariano Rajoy, aparezca diluido entre las nubes de palabras de su partido.

Además de estas imágenes el uso relevante de determinadas palabras denota que los asuntos de actualidad hacen mella en la agenda discursiva de cada uno de los partidos, pero lo hacen de forma diferente. Así, por ejemplo, del estudio realizado se deduce fácilmente que la moción de censura presentada por Podemos al gobierno de Rajoy ha incidido en los discursos de todos los partidos estatales -Ciudadanos, PP y PSOE- pero no tanto de los partidos nacionalistas -Compromís y PNV-. Se deduce también que al PNV le preocupan pocas cosas más allá de los presupuestos (cupo) mientras que Compromís está más vinculado a determinados asuntos en clave valenciana. Ciudadanos, por su parte, aprovecha insistentemente los casos de corrupción para marcar diferencias con el PP al que estos asuntos de actualidad son los que más afectan (contrapartida a Ciudadanos) sin olvidar los presupuestos (contrapartida al PNV) y la moción de censura (contrapartida a Podemos). Podemos no parece verse afectado por ningún tema de actualidad, al menos de forma relevante, a no ser la incidencia de Venezuela en sus tweets. El PSOE, por su parte, se vio afectado al principio de la serie por la negociación de tratado CETA con un debate interno cuyas consecuencias se han visto muy a posteriori en forma de abstención en el Congreso de los Diputados.

\subsection{Primarias del PSOE}

La coincidencia en el tiempo entre el estudio realizado y la celebración de las primarias en el PSOE nos han permitido testar la incidencia en las redes de una campaña entre candidatos en una elección de corte presidencial. A continuación, se describen en términos muy generales los resultados de la investigación.

\section{PATXI LÓPEZ}

La campaña de Patxi López aparece orquestada sólo en torno a la figura del líder -\#socialistasconpatxi y \#conpatxiganamostodos. Es una campaña que dice pocas cosas, sin un discurso diferenciador potente, más allá del llamamiento a la unidad, y, por tanto, condenada al fracaso si el líder no lo es ya con anterioridad. Los acontecimientos de la campaña en la red se desarrollan con el siguiente iter:

\section{- Febrero}

- Sólo destaca el hashtag \#socialistasconpatxi (10\%).

- También pero a distancia partido, unido (sumados 4\%).

- En tercer lugar, gracias.

- Marzo

- Sigue el hashtag \#socialistasconpatxi $(7,4 \%)$.

- Se añade el hashtag \#conpatxiganamostodos $(4,75)$. 
Aparecen algo destacadas, aunque poco, expresiones como: gracias, seguimos, sumando (juntas $11 \%$ ).

- Abril

- Siguen las marcas anteriores pero los hashtags se reducen a un $5 \%$ juntos.

- Aparecen por primera vez referencia a Patxi $(2,3 \%)$ y a López (1,6\%), juntas $4 \%$.

- Mayo

- Desaparecen los hashtags.

- Destaca por encima de todo la referencia de Patxi López (juntas 6,5\%).

- Aparecen con fuerza Pedro y mentiroso (juntas 3,3\%).

\section{PEDRO SÁNCHEZ}

La campaña de Pedro Sánchez arranca pronto con fuerza, asociándose al término izquierda y al hashtag \#nuevoPSOE, por tanto, marcando el territorio de juego. Ese mensaje de contenido político lo afianzará a partir de marzo con la marca de claras resonancias políticas \#siessi, recordatorio de su defenestración en el famoso Comité Federal. Significativa es la presencia destacada entre ese grupo de \#valenciaambpedro, federación cuyo secretario general, Ximo Puig, se había posicionado a favor de Susana Díaz y dónde Pedro Sánchez va a tener el apoyo de un grupo entre cuyos líderes se encuentra José Luis Ábalos, futuro secretario de organización del partido y portavoz en el Congreso. Los acontecimientos de la campaña en la red se desarrollan con el siguiente iter:

\section{- Febrero}

- Destaca por encima de todo Pedro (1,3\%).

- A continuación izquierda (1,2\%).

- En tercer lugar, \#somossocialistas (1\%).

- Después un grupo indiferenciado donde destacan algo partido, militantes, \#elnuevopsoe, proyecto, gestora o España.

- Marzo

- Destaca ahora \#siessi (1,6\%), un poco por encima de Pedro $(1,4 \%)$.

- A continuación, \#somossocialistas e izquierda (1\%).

- Después, un grupo indiferenciado donde destacan primarias, partido, militantes,...

- Presencia destacada entre ese grupo del hashtag \#valenciaambpedro.

- Abril

- Repite destacado \#siessi (2,1\%), seguido de Pedro (1,6\%).

- A continuación, \#somossocialistas (1\%) e izquierda (1\%).

- Después, un grupo indiferenciado donde destacan partido, militantes, izquierda...

- Aparecen también, fruto de la presentación de la moción de censura, Iglesias y Rajoy.

- Ni siquiera en estos momentos Susana es relevante. 
Mayo

- Pasadas las primarias, Pedro (1,6\%) es desbancado por Iglesias (3\%).

Quedan, pues, en un segundo lugar, Pedro, \#siessi $(1,4 \%)$ o \#somossocialistas.

- Destacable la referencia otra vez valenciana de ambPedro $(0,7 \%)$.

Aparece gracias.

\section{SUSANA DÍAZ}

La campaña de Susana Díaz tarda en arrancar lo que hace que en el mes de febrero no aparezca un perfil definido de la candidata en la red a la que se le asocia todavía con Andalucía. Es en marzo cuando arranca con fuerza su presencia. Se trata de afianzar su imagen de líder a partir de su propio nombre, si bien no consigue marcar un territorio propio y definido con contenido político. Su apuesta por el hashtag \#100por100PSOE no hace más que identificarla con el partido, como también aparecen identificados el resto de sus contrincantes. El hashtag \#Susanailusiona es un tanto infantil. La misma tónica se mantiene en abril, diluyéndose a partir de mayo una vez celebrada la elección del nuevo líder del PSOE. Los acontecimientos de la campaña en la red se desarrollan con el siguiente iter:

\section{Febrero}

- No aparece ninguna palabra especialmente destacada, siendo Andalucía (1\%) la más citada (también aparece Asturias, aunque lejos), si bien, si sumamos todas las referencia a izquierda y similares, sería esta la expresión dominante, aunque también destaca, en cualquier caso, la referencia a Centro.

- Y los hashtags \#psoe y \#susanadiazcsr.

- Algo menos las referencias al partido en distintas versiones -gestora, primarias- $y$ a gobierno.

- Marzo

- Sigue sin aparecer una palabra destacada, la más citada es la marca \#100por100psoe $(0,8 \%)$, si bien su sumamos todas las referencias a Susana Díaz -susana, diaz, susanadiaz, \#susanadiaz, \#susanadíaz- sería esta la destacada.

- Siguen apareciendo las referencias al partido, al gobierno y el hashtag \#psoe, muy alejada el hashtag \#susanailusiona.

- Aparece con fuerza la referencia a España.

- Abril

- Destaca el hashtag \#100por100psoe (1\%).

- Le siguen las referencias a Susana Díaz.

- Siguen partido, socialistas, gobierno, España.

- Aparece Iglesias.

Mayo

- Destaca avales.

- Le sigue Iglesias.

- Y ya en tercer lugar Susana y los diferentes hashtags de Susana.

- Finalmente primarias, partido, Andalucía y, algo más lejos, España y Pedro. 
En definitiva, el seguimiento de la campaña a través de las redes utilizando el análisis de nubes de palabras permite tener un control de su evolución y de las debilidades y fortalezas de los distintos planteamientos estratégicos.

\section{Conclusiones}

En este trabajo hemos centrado nuestro interés en el comportamiento de algunos de los principales partidos políticos españoles -aparato, militantes, simpatizantes digitales comprometidos- en los procesos de construcción de la agenda pública-agenda setting o agenda building- en las redes sociales españolas. A fin de analizar las consecuencias de ese comportamiento en términos de imágenes y atributos transmitidos por cada partido político ha sido necesario el desarrollo de herramientas Big Data que permiten utilizar algorítmica avanzada en las plataformas digitales y analizar los grandes volúmenes de datos generados en tiempo real. El estudio realizado ha servido para corroborar los rendimientos de la utilización de esta metodología para analizar el comportamiento de los partidos en el campo de la comunicación política.

Los resultados de la investigación permiten afirmar, a su vez, la importancia de estos estudios dado que los partidos políticos -aparatos, militantes y simpatizantes digitales comprometidos- tienen comportamientos diferenciados en las redes que transmiten por este cauce atributos e imágenes de sí mismos que, dada la creciente utilización de las mismas -especialmente por las generaciones más jóvenes-, permiten suponer que tienen un fuerte impacto en el imaginario de la opinión pública sobre los partidos y que posiblemente por ello también tiene efectos en la construcción de la agenda pública. La descripción en el texto de las nubes de palabras generadas por cada partido en las redes sociales ha permitido hacerse una idea cabal de la imagen con sus fortalezas y debilidades que trasladan, consciente o inconscientemente, a los ciudadanos y ciudadanas que participan en la red.

\section{Referencias}

Aruguete, N. (2015). El poder de la agenda. Política, medios y público. Argentina: Biblos / Cuadernos de Comunicación.

Aruguete, N. (2017). Agenda building. Revisión de la literatura sobre el proceso de construcción de la agenda mediática. doi:10.11144/Javeriana.syp36-70.abrl

Becker, L., McCombs, M., y McLeod, J. (1975). The Development of Political Cognitions. In Chafee, S. C. (Ed.) Political Communication: Issues and Strategies for Research. London: Sage.

Boyd, D. M. y Ellison, N. B. (2007). Social Network Sites: Definition, History, and Scholarship. In Journal of Computer-Mediated Communication 13.1, 210-230. issn: 1083-6101. doi: 10.1111/j.1083-6101.2007.00393.x.

Cohen, B. (1963). The Press and the Foreign Policy. Pricenton, NJ: University Press.

Conwy, B.A., Kenski, K. y Wang, D. (2015) The Rise of Twitter in the Political Campaign: Searching for Intermedia Agenda-Setting Effects in the Presidential Primary. In Journal of Computer-Mediated Communication, 20. url: https://doi.org/10.1111/jcc4.12124

Dean, J. y Ghemawat, S. (2004). MapReduce: Simplified Data Processing on Large Clusters. In Dokoohaki, N. et al. (2015). Predicting Swedish elections with Twitter: A case for stochastic link structure analysis. In 2015 IEEE/ACM International Conference on Advances in Social Networks Analysis and Mining (ASONAM), 1269-1276. doi: 10.1145/2808797.2808915. 
Fatta, G. Di et al. (2015). Big Social Data and Political Sentiment: The Tweet Stream during the UK General Election 2015 Campaign. In 2015 IEEE International Conference on Smart City/SocialCom/SustainCom (SmartCity), 293-298. doi: 10 . 1109 / SmartCity.2015.87.

Festinger, L. (1975). La teoría de la disonancia cognoscitiva. Madrid: Instituto de Estudios Políticos.

Fleur, M. L. de y Ball-Rokeach, S. (1986). Teorías de la comunicación. Barcelona: Paidós.

Gelado, R., Rubira, R. y Navío, M. (2019) Comunicando en los nuevos entornos. El impacto de Twitter en la Comunicación Política española en Revista Mediterránea de Comunicación. 2019, 10 (2): 73-84. doi:10.14198/MEDCOM2019.10.2.11

Ghemawat, S., Gobioff, H. y Leung, S. (2003). The Google File System. In Hasan, M. y col. (2017). Using Social Sensing to Discover Trends in Public Emotion. In 2017 IEEE 11th International Conference on Semantic Computing (ICSC), 172-179. doi: 10.1109/ICSC .2017.76.

González, F. (2019) Big Data, algoritmos y política: las ciencias sociales en la era de las redes digitales. In Cinta Moebio 65: 267-280. doi: 10.4067/S0717-554X2019000200267

Kwak, H. et al. (2010). What is Twitter, a social network or a news media? In Proceedings of the 19th International Conference on World Wide Web. WWW '10. Raleigh, North Carolina, USA: ACM, 591-600. doi: 10. 1145/1772690 .1772751. url: http://doi.acm. org/10.1145/1772690.1772751.

Iguarta, J. J. y Humanes, M. L. (2004). Teoría e investigación en comunicación social. Madrid: Síntesis.

IntelligenceCompass (2010). Informe sobre políticas y redes sociales: https://mouriz.files. wordpress.com/2010/10/informe-politicos-y-redes-sociales.pdf

Sierra, J. y Lavín, J.M. coords. (2019) Redes sociales, tecnologías digitales y narrativas interacticas en la sociedad de la información, McGraw-Hill Interamericana de España.

Katz, E. \& Lazarsfeld, P. F. (1975). La influencia personal. Barcelona: Hispano Europa.

Kosicki, G. (1993): Problems and opportunities in agenda setting research. Journal of Communication 43.

Kruikemeier, S. (2014). How political candidates use Twitter and the impact on votes. Computers in Human Behavior 34: 131-139. https://doi.org/10.1016/j.chb.2014.01.025

Lazarsfeld, P. F., Berelson, B. B. y McPhee, W. (1954). Voting: a Study of Opinion Formation During a Presidential Campaign. Chicago: University of Chicago Press.

Lippmann, W. (2003). La opinión pública. Madrid: Langre.

López García, G. (2006). Comunicación digital y líneas de fractura en el paradigma de la agenda setting. Doxa Comunicación 4, 37-58.

Mayank, D., Padmanabhan, K. y Pal, K. (2016). Multisentiment modeling with scalable systematic labeled data generation via word2Vec clustering. In 2016 IEEE 16th International Conference on Data Mining Workshops (ICDMW), 952-959. doi: 10.1109/ICDMW.2016.0139.

McCombs, M. (2006). Estableciendo la agenda. Barcelona: Paidós.

McCombs, M. y Shaw, D. (1972). The agenda setting function of mass media. Public Opinion Quarterly, 31, 2.

McCombs, M. y Shaw, D. (1977). Agenda Setting and the Political Process. In Shaw, D. 
y MacCombs, M. (Eds.) The Emergence of American Political Issues: the Agenda Setting Function of the Press. St. Paul, Minnesota: West Publishing Co.

Noelle-Neumann, E. (1995). La espiral del silencio. Barcelona: Paidós.

Novak, P. K. et al. (2015). Sentiment of Emoji. In CoRR abs/1509.07761. url: http://arxiv. org/abs/1509.07761. Romero, R. C. (2015). Politics 2.0 ICTs in Costa Rica's 2014 Presidential Campaign. In 2015 International Conference on Information Society (i-Society), 115-120. doi: 10.1109/i- Society.2015. 7366870. - (2016). Internet politics: Towards a social networking typology 2014; Costa Rica municipal elections analysis. In 2016 International Conference on Information Society (i-Society), 149-154. doi: 10.1109/i-Society.2016.7854201.

Robles, J.M. y Marco, E. de (2019) Las redes sociales como nuevo elemento de desigualdad de la comunicación partidista. In Lagares, N, Ortega, C. y Oñate, P., eds., Las elecciones autonómicas de 2015 y 2016. Madrid. Centro de Investigaciones Sociológicas.

Rubio Ferreres, J. M. (2009). Opinión pública y medios de comunicación. Teoría de la agenda setting. Gaceta de Antropología, 24.

Sartori, G. (2007). Qué es la democracia. Madrid: Taurus.

Seethaler, J. y Melischek, G. (2919) Twitter as a tool for agenda building in election campaigns? The case of Austria. url: https://doi.org/10.1177/1464884919845460

Shafiq, M. Z. et al. (2013). Identifying Leaders and Followers in Online Social Networks. In IEEE Journal on Selected Areas in Communications 31.9, 618-628. issn: 0733-8716. doi: 10.1109/JSAC.2013.SUP.0513054.

Solis, D. (2001). Ponencia Jornadas sobre Gestión en Organizaciones del Tercer Sector en la Universidad Di Tella de Buenos Aires: https://prezi.com/7wyjlkxnv1ot/ponencia-jornadas-sobre-gestion-en-organizaciones-del-terce/

Vara Miguel, A. (2001). La influencia de los partidos políticos en la construcción de la agenda mediática y el rol de los periodistas como mediadores sociales. Aproximación teórico-práctica a las teorías de la agenda setting y de la agenda building. Tesis doctoral. Pamplona: Universidad de Navarra.

Wang, H. et al. (2012). A System for Real-time Twitter Sentiment Analysis of 2012 U.S. Presidential Election Cycle. In Proceedings of the ACL 2012 System Demonstrations. ACL '12. Jeju Island, Korea: Association for Computational Linguistics, 115-120. url: http:// dl.acm.org/citation.cfm?id= 2390470.2390490.

Watts, D. et al. (2016). Tweet sentiment as proxy for political campaign momentum. In 2016 IEEE International Conference on Big Data (Big Data), 2475-2484. doi: 10.1109/ BigData.2016.7840885.

Yeruva, S. y Devi, T. (2014). A Study on Direct Influence in Online Social Networks. In 2014 International Conference on Intelligent Computing Applications, 387-391. doi: 10.1109/ ICICA.2014.85.

Vergeer, M. (2015) Twiter and Political Campaigning. In Sociology Compass, September. url: https://doi.org/10.1111/soc4.12294

Weaber, D. H., Graber, D. A., McCombs, M. y Eyal, C. H. (1981). Media agenda setting in a presidential election. New York: Praeger. 